\title{
EFEKTIVITAS BIMBINGAN KELOMPOK MENGGUNAKAN PERMAINAN SIMULASI DALAM MENINGKATKAN KOHESI SOSIAL
}

\author{
Suchiwaty Yusza1, Firman Firman ${ }^{2}$, Daharnis Daharnis ${ }^{3}$ \\ ${ }^{1}$ Universitas Negeri Padang, Padang, Indonesia, $\triangle$ (e-mail) suchiwaty.lsm@gmail.com \\ ${ }^{2}$ Universitas Negeri Padang, Padang, Indonesia, $\square$ (e-mail) firman@konselor.org \\ ${ }^{3}$ Universitas Negeri Padang, Padang, Indonesia, $₫$ (e-mail) daharnis@fipunp.ac.id
}

\begin{abstract}
Abstrak
Kohesi sosial merupakan kesatuan serta hubungan yang terjadi antara individu, termasuk siswa sekolah menengah. Kohesi sosial yang rendah ditunjukkan ada rasa saling bermusuhan, agresif, serta rasa kesenangan atas kegagalan orang lain atau kelompok lain. Masalah yang sering dialami siswa adalah tidak mampu menjalin kerjasama, tidak mempercayai kemampuan temannya sendiri dan terjadinya persaingan. Layanan bimbingan kelompok di sekolah masih belum berhasil menyelesaikan permasalahan yang terkait dengan kohesi sosial. Penelitian ini bertujuan mengungkapkan efektifitas bimbingan kelompok menggunakan permainan simulasi dalam meningkatkan kohesi sosial siswa. Penelitian menggunakan pendekatan kuantitatif dengan desain quasi eksperimen. Subjek penelitian siswa SMA Dewantara sebanyak 14 orang, masing-masing 7 orang kelompok eksperimen dan 7 orang kelompok kontrol. Pengumpulan data dengan kuesioner menggunakan skala Likert, serta data dianalisis dengan Wilcoxon Signed Ranks Test. Berdasarkan hasil penelitian ditemukan bimbingan kelompok menggunakan permainan simulai efektif untuk meningkatkan kohesi sosial siswa sekolah menengah.
\end{abstract}

Keywords: Kohesi Sosial, Bimbingan Kelompok, Permainan Simulasi

\footnotetext{
(c) (1)

This is an open access article distributed under the Creative Commons 4.0 Attribution License, which permits unrestricted use,

distribution, and reproduction in any medium, provided the original work is properly cited. $\odot 2018$ by author and Faculty of education, Universitas Negeri Padang.
}

\section{PENDAHULUAN}

Kohesi sosial merupakan kemampuan suatu kelompok untuk menyatu agar individu tetap tinggal di dalamnya dan ikut aktif berperan dalam kelompok agar semua anggota kelompok teta kompak (Arthur \& Emily, 2010). Tingkatan kohesi sosial dapat ditujukan oleh hubungan individu dengan anggota kelompok. Anggota kelompok dapat mempelajari bagaimana perilaku yang kompak terhadap kelompok sosial dengan memiliki rasa kekompakan secara keseluruhan antara setiap anggotanya. Kohesi sosial sebagai daya saling ketertarikan antar anggota kelompok yang berkeinginan untuk tetap tinggal dalam kelompok 
(Johnson \& Johnson; Budiharto, 2004; Trihapsari \& Nashori, 2011). Seiring dengan pengalaman yang didapat oleh siswa, dalam bergaul di kehidupan kelompok sosial, maka siswa tersebut akan membentuk kesatuan kelompok dengan individu lain ataupun siswa lain di sekolah yang bisa disebut juga kohesi sosial. Kohesi sosial merupakan kekuatan yang mendorong anggota kelompok untuk tetap tinggal dan kecil kemungkinannya untuk meninggalkan kelompok tersebut (Collins \& Raven; Rachmat, 2005; Herlianto, Tadjri \& Saraswati, 2012). Untuk meningkatkan kohesi sosial siswa secara optimal, terdapat salah satu layanan di dalam bimbingan dan konseling, yang merupakan salah satu layanan dasar yaitu layanan bimbingan kelompok.

Bimbingan kelompok adalah salah satu dari layanan bimbingan dan konseling yang diselenggarakan secara kelompok dengan mengikutkan sejumlah anggota dengan memanfaatkan dinamika kelompok. Kegiatan bimbingan kelompok akan terlihat hidup jika di dalamnya terdapat dinamika kelompok. Dinamika kelompok adalah media efektif bagi anggota kelompok dalam mengembangkan berbagai aspek-aspek positif seperti: mengembangkan kemampuan komunikasi, kepercayaan diri, dan solidaritas anggota kelompok. Layanan bimbingan kelompok adalah kegiatan yang memungkinkan siswa secara bersama-sama memperoleh bahan dari narasumber (terutama guru bimbingan dan konseling) yang bermanfaat untuk kehidupan sehari-hari baik sebagai individu maupun sebagai pelajar, anggota keluarga dan masyarakat (Sukardi, 2003; Suhardita, 2011; Sampurnawati, 2014; Dachmiati \& Amalia, 2017)

Bimbingan kelompok bertujuan untuk memungkinkan siswa secara bersama memperoleh berbagai bahan dan narasumber (terutama guru bimbingan dan konseling) yang bermanfaat untuk kehidupan sehari-hari. Layanan bimbingan kelompok dimaksudkan untuk mencegah berkembangnya masalah atau kesulitan pada klien (Juntika, 2007; Putra, Daharnis \& Syahniar, 2013). Maka dari itu, bimbingan kelompok dapat membantu siswa yang berkenaan dengan kemampuan sosial.

Berdasarkan informasi dari guru BK di SMAN 1 Dewantara, masih ada siswa di dalam kelas pada saat guru mata pelajaran memberikan tugas dengan berbentuk kelompok, siswa tidak mau bekerjasama dan berinteraksi dengan anggota yang baru. Karena anggota di dalam kelompoknya bukan teman terdekatnya, sehingga saat mengerjakan tugas kelompok, tidak ada rasa saling percaya dengan kemampuan anggota-anggota kelompoknya. Oleh karena itu, anggota kelompok dengan yang lainnya tidak memiliki rasa kesatuan serta keeratan yang utuh dalam hubungan sosial di dalam kelompok tersebut. Sehingga di dalam kelompok tersebut terjadi persaingan. Guru BK sudah melaksanakan layanan bimbingan kelompok, akan tetapi pada saat melaksanakan layanan bimbingan kelompok, masih ada anggota kelompok yang pasif, artinya kurang aktif. Masih ada saling menyindir pada saat mengemukakan pendapat, misalnya anggota siswa tidak menerima perlakuan sindiran yang kasar terhadap anggota yang lainnya.

Kurangnya keefektifan siswa dalam menjalin keakraban dengan anggota yang lain dan persaingan yang kurang baik dalam pelaksanaan bimbingan kelompok, berdasarkan hal tersebut peneliti ingin meningkatkan kohesi sosial siswa melalui bimbingan kelompok dengan menggunakan permainan simulasi, dimana permainan simulasi dapat membantu untuk memotivasi siswa dengan suasana kelompok yang tidak meresahkan, menakutkan dan dapat 
memotivasi siswa untuk merangsang berbagai bentuk belajar, seperti belajar tentang persaingan, kerjasama, empati sosial, keterampilan dan kemampuan berpikir kritis.

Berdasarkan fenomena yang ada di sekolah tersebut, maka peneliti mencoba layanan bimbingan kelompok menggunakan permainan simulasi dalam meningkatkan kohesi sosial. Inti permasalahan yang dikaji dalam penelitian ini, sehingga peneliti mengambil judul "Efektivitas layanan bimbingan kelompok menggunakan permainan simulasi dalam memningkatkan kohesi sosial siswa".

\section{METODOLOGI}

Penelitian ini menggunakan pendekatan kuantitatif, metode penelitian kuasi eksperimen. Salah satu desain yang tergolong kuasi eksperimen adalah the non equivalent control group, subjek yang diambil tidak secara random, baik kelompok eksperimen maupun kelompok kontrol (Yusuf, 2014). Subjek penelitian ini dilaksanakan pada siswa kelas XI SMAN 1 Dewantara. Instrument dalam penelitian ini adalah angket kohesi sosial. Analisis data dibantu dengan menggunakan program SPSS versi 20.00.

\section{HASIL PENELITIAN}

Secara spesifik penelitian ini adalah untuk mendeskripsikan efektivitas bimbingan kelompok menggunakan permainan simulasi dalam meningkatkan kohesi sosial siswa. Data yang di peroleh adalah hasil pretest dan posttest berkaitan dengan kohesi sosial. Dapat dilihat Tabel 1.

Table 1. Perbandingan Kohesi Sosial Siswa Kelompok Eksperimen Pretest-Posttest

\begin{tabular}{|c|c|c|c|c|c|c|}
\hline \multirow{2}{*}{ No } & \multirow{2}{*}{$\begin{array}{c}\text { Kode Respon } \\
\text { Den }\end{array}$} & \multicolumn{2}{|c|}{ Pretest } & \multicolumn{2}{|c|}{ Posttest } & \multirow{2}{*}{ Selisih } \\
\cline { 2 - 6 } & SQ & 130 & Sedang & 163 & Tinggi & 33 \\
\hline 2 & YY & 132 & Sedang & 175 & Sangat Tinggi & 43 \\
\hline 3 & SRF & 100 & Rendah & 163 & Tinggi & 63 \\
\hline 4 & MUH & 130 & Sedang & 178 & Sangat Tinggi & 48 \\
\hline 5 & LZ & 128 & Sedang & 163 & Tinggi & 35 \\
\hline 6 & EE & 132 & Sedang & 152 & Tinggi & 20 \\
\hline 7 & RR & 100 & Rendah & 163 & Tinggi & 63 \\
\hline \multicolumn{2}{|r|}{ Rata-rata keseluruhan } & $\mathbf{1 2 1}$ & Sedang & $\mathbf{1 6 5}$ & Tinggi & $\mathbf{4 4}$ \\
\hline
\end{tabular}

Berdasarkan Tabel 1 terlihat bahwa kohesi sosial siswa kelompok eksperimen mengalami peningkatan setelah diberikan layanan bimbingan kelompok menggunakan 
permainan simulasi. Sebelum diberikan layanan bimbingan kelompok menggunakan permainan simulasi, rata-rata skor pretest sebesar 121 dan berada pada kategori sedang. Setelah diberikan layanan bimbingan kelompok menggunakan permainan simulasi rata-rata skor posttest meningkat menjadi sebesar 165 dan berada pada kategori tinggi. Kemudian dapat dilihat terladinya peningkatan kohesi sosial siswa kelompok eksperimen yang diberikan layanan bimbingan kelompok menggunakan permainan simulasi. Kohesi sosial siswa pada kelompok kontrol mengalami peningkatan setelah diberikan layanan bimbingan kelompok tanpa menggunakan permainan simulasi. Sebelum diberikan layanan bimbingan kelompok rata-rata skor pretest sebesar 122 dan berada pada kategori sedang. Setelah diberikan layanan bimbingan kelompok tanpa menggunakan permainan simulasi rata-rata skor posttest meningkat menjadi sebesar 151 dan berada pada kategori tinggi.

Kemudian untuk menguji posttest kelompok eksperimen dengan diberikan perlakuan berupa bimbingan kelompok menggunakan permainan simulasi dengan kelompok control tanpa perlakuan berupa bimbingan kelompok tanpa menggunakan permainan simulasi, hasilnya yaitu: "Terdapat perbedaan yang signifikan kohesi sosial siswa kelompok eksperimen dengan kelompok kontrol”. Untuk menguji hipotesis ketiga ini digunakan teknik Kolmogorov Smirnov 2 Independent Samples dengan menggunakan bantuan SPSS versi 20.00. Berdasarkan hal tersebut didapatkan hasil pengujian seperti terangkum pada Tabel 2.

\section{Tabel 2. Hasil Analisis Tes Kolmogorov Smirnov 2 Independent pada Posttest Kohesi Sosial Siswa Kelompok Eksperimen dan Kelompok Kontrol}

Test Statistics(a)

\begin{tabular}{|ll|r|}
\hline & & \multicolumn{1}{|c|}{ KohesiSosial } \\
\hline Most Extreme Differences & Absolute &, 857 \\
& Positive &, 000 \\
& Negative &,- 857 \\
Kolmogorov-Smirnov Z & & 1,604 \\
Asymp. Sig. (2-tailed) & &, 012 \\
\hline
\end{tabular}

a Grouping Variable: Subjek

Berdasarkan data Tabel 2 di atas, dapat terlihat $\mathrm{Z}$ adalah 1,604 dengan memperoleh Asymp. Sig. (2-tailed) kohesi sosial siswa kelompok eksperimen dan kelompok kontrol sebesar 0,012. Dari hasil tersebut maka Ho ditolak dan H1 diterima. Dengan demikian, maka hipotesis ketiga yang diuji dalam penelitian ini dapat diterima, yaitu "Terdapat perbedaan yang signifikan kohesi sosial siswa antara kelompok eksperimen dengan kelompok kontrol".

Hasil temuan juga dapat mendukung bahwasannya, hasil penelitian menunjukkan bahwa pedoman bimbingan kelompok efektif untuk meningkatkan pemikiran logis moral siswa dan mencegah tindakan kekerasan di kalangan siswa sekolah menengah atas (Rezki, Firman \& Karneli, 2018). Kohesi sosial yang efektif dapat membina rasa sikap kekompakan yang koherensi (Kaur, Hasim \& Norman, 2017). Kemudian kohesi sosial juga dapat mengurangi konflik yang sering terjadi dan dapat membantu individu untuk berpartisipasi dengan anggota kelompok lainnya (Suayb, 2010). Oleh karena itu, dengan melalui bimbingan kelompok menggunakan permainan simulasi dapat membantu siswa, seperti keterlibatan dalam kerja 
kelompok dan mau ikut berpartisipasi dalam menyelesaikan tugas-tugas kelompok (Demis \& Brian, 2018).

\section{SIMPULAN}

Berdasaarkan hasil penelitian ini dapat disimpulkan bahwa layanan bimbingan kelompok menggunakan permainan simulasi efektif dalam meningkatkan kohesi sosial siswa. Hasil penelitian yang dilakukan terhadap kelompok eksperimen dan kelompok kontrol mengenai kohesi sosial siswa menunjukkan bahwa adanya peningkatan pada kelompok eksperimen secara signifikan. Pada kelompok eksperimen dan kelompok kontrol sebelum perlakuan memiliki hasil yang setara dalam peningkatan kohesi sosial. Hal ini dapat dibuktikan dengan melihat hasil pretest pada kedua kelompok. Setelah diberikan perlakuan berupa layanan bimbingan kelompok menggunakan permainan simulasi dalam meningkatkan kohesi sosial dan kelompok eksperimen, secara signifikan mengalami perubahan yang lebih baik atau meningkat.

\section{DAFTAR RUJUKAN}

Arthur, S. R. \& Emily S. R. 2010. Kamus Psikologi. Yogyakarta: Pustaka Pelajar.

Dachmiati, S., \& Amalia. 2017. Layanan Bimbingan Kelompok untuk Meningkatkan Self-Esteem Siswa. Journal Fokus Konseling. Vol. 3 (2)

Demis. E. G. \& Brian. J. 2018. Respect the Technique: Status-based Respect Increases Minority Group Social Cohesion With Majority Groups, While Also Increasing Minority Collective Action Tendencies. Journal of Social Psychology. Vol. 158 (2).

Herlianto. P., Tadjri. I., \& Saraswati. S. 2012. Hubungan Kohesivitas dengan Dinamika Kelompok dalam Bimbingan Kelompok pada Siswa SMPN 13 Semarang. International Journal of Guidance and Counseling: Theory and Application. Vol. 1 (2).

Kaur. A., Hashim. R. \& Noman. M. 2017. Defining Intercultural Education for Social Cohesion In Malaysian Context. International Journal of Multicultural Education. Vol 19 (2).

Putra S. A., Daharnis \& Syahniar. 2013. Efektivitas Layanan Bimbingan Kelompok dalam Meningkatkan Self Effecacy Siswa. Jurnal Ilmiah Konseling. Vol. 2 (2).

Rezki. H, Friman \& Karneli. Y. 2018. Improving Students' Moral Logical Thinking and Preventing Violent Acts Through Group Counseling in Senior High Schools. Advanced Science Latters. Vol. 24 (1).

Sampurnawati, E. 2014. Upaya Meningkatkan Motivasi Belajar Melalui Bimbingan Kelompok Pada Siswa. In Kes. Vol 1 (2)

Shuayb. M. 2016. Education for Social Cohesion Attempts In Lebanon: Reflections and The 1994 and 2010 Education Reforms. Education as Change. Vol. 20 (3).

Sihotang, N., Yusuf, A. M., \& Daharnis, D. 2016. Pengaruh Layanan Bimbingan Kelompok terhadap Pencapaian Tugas Perkembangan Remaja Awal dalam Aspek Kemandirian Emosional (Studi Eksperimen di SMP Frater Padang). Konselor. Vol. 2 (4). 
Situmorang, R. S. R., Saman, S., \& Susilo, F. (2014). Jenis Kohesi Leksikal dalam Novel Memang Jodoh Karya Marah Rusli. Jurnal Pendidikan dan Pembelajaran. Vol. 3 (6)

Suhrdita, K. 2011. Efektivitas Penggunaan Teknik Permainan dalam Bimbingan Kelompok untuk Meningkatkan Percaya Diri Siswa. Edisi Khusus. Vol. 8 (1).

Trihapsari. V. R. \& Nashori. F. 2011. Kohesivitas Kelompok dan Komitmen Organisasi pada Financial Advisor Asuransi "X" Yogyakarta. Proyeksi. Vol. 6 (2).

Wijaya, E., dkk. 2014. Peningkatan Kohesi Sosial Menggunakan Bimbingan Kelompok. Jurnal Bimbingan dan Konseling. Vol.2 (2).

Yusuf. A. 2013. Metode Penelitian: Kuantitatif, Kualitatif dan Penelitian Gabungan. Padang: UNP 